\title{
Stochastic analysis of groundwater temperature timeseries for characterizing check dams efficiency: case study on a Managed Aquifer Recharge site (Veneto, Italy)
}

\author{
Analisi stocastica di serie temporali della temperatura delle acque sotterranee per \\ caratterizzare l'efficienza di rampe fluviali: caso studio in un sito Managed Aquifer Recharge \\ (Veneto, Italia)
}

Mara Meggiorin, Giulia Passadore, Silvia Bertoldo, Andrea Sottani, Andrea Rinaldo

Riassunto: Questo studio utilizza un'analisi stocastica sulle serie temporali delle temperature per investigare le connessioni idrauliche tra le acque del fiume Brenta e le acque sotterranee. Gli andamenti delle serie temporali vengono analizzati per comprendere la reciproca influenza di questi due compartimenti e per valutare l'efficienza di una rampa stabilizzatrice di fondo realizzata nel letto del fiume per aumentare la ricarica all'acquifero. I dati a disposizione provengono da un idrometro, due punti di monitoraggio delle acque sotterranee nelle sponde del fiume e un ulteriore punto a distanza maggiore per rappresentare l'andamento termico dell'acquifero indisturbato dalla dispersione fluviale. Tre differenti analisi sono applicate ai dati sperimentali: analisi di Fourier, autocorrelazione e correlazione di Pearson in una finestra temporale mobile. I risultati dei punti monitorati nelle sponde

Keywords: stream seepage, temperature, stochastic analysis, Managed Aquifer Recharge.

Parole chiave: ricarica fluviale, temperatura, analisi stocastica, Managed Aquifer Recharge.

\section{Mara MEGGIORIN 夆”。}

Dipartimento di Ingegneria Civile, Edile e Ambientale, Università di Padova Sinergeo Srl - Vicenza, Italy

mara.meggiorin@dicea.unipd.it

\section{Giulia PASSADORE}

Dipartimento di Ingegneria Civile, Edile e Ambientale, Università di Padova giulia.passadore@dicea.unipd.it

\section{Silvia BERTOLDO, Andrea SOTTANI \\ Sinergeo Srl - Vicenza, Italy \\ sbertoldo@sinergeo.it \\ asottani@sinergeo.it}

\section{Andrea RINALDO}

Dipartimento di Ingegneria Civile, Edile e Ambientale, Università di Padova Laboratory of Echohydrology (ECHO/IIE/ENAC), École Polytechnique Fédérale de Lausanne, Switzerland

andrea.rinaldo@epfl.ch

Ricevuto/Received: 14 October 2019-Accettato/Accepted: 18 December 2019 Pubblicato online/Published online: 20 December 2019

This is an open access article under the CC BY-NC-ND license:

http://creativecommons.org/licenses/by-nc-nd/4.0/

(C) Associazione Acque Sotterranee 2019 del fiume sono confrontati con quelli dei possibili flussi affluenti per valutare se il piezometro risente maggiormente della dispersione fluviale o del flusso sotterraneo regionale. Le tre analisi concordano nei risultati evidenziando un aumento dell'area fluviale di dispersione e una diminuzione della ricarica all'acquifero dopo alcuni anni di operatività della rampa.

Abstract: In order to investigate bydraulic connections between the Brenta river and its groundwater aquifers, this work performs a stochastic analysis of measured groundwater temperature timeseries. The aim is to compare their trends to verify their mutual influence in stream seepage pathways. Additionally, the study wants to assess whether a large check dam, built across the river to increase aquifer recharge, is working properly. Field data were obtained by a water gauge placed directly into the stream, by two riverbank control points and by a monitoring well representing the regional groundwater thermal trend. Timeseries were evaluated by applying three different analyses - Fourier analysis, autocorrelation and sliding time-window Pearson correlation. Control points results were compared to the inflows to sort whether the aquifer is locally more affected by river dispersion or by regional groundwater flow. The three considered methods substantially agree in showing an increase of the seepage area upstream of the check dam and, at the same time, a marked reduction of groundwater recharge after few years of operation.

\section{Introduction}

In recent years, increasing attention is devoted to groundwater resources and their sustainable use. With this perspective, studies and real actions have been done to improve its sustainability, analysing different aspects, including Managed Aquifer Recharge (MAR) activities, based on interactions between surface water and groundwater.

Depending on relative hydraulic heads, groundwater can be drained or recharged by the river. Both flow directions are essential for hydraulic and ecologic systems: the groundwater drainage is essential to fluvial ecosystems, ensuring a minimal water flow and a moderate temperature (Hayashi and Rosenberry 2002) and river seepage is important on a number of counts (Rinaldo et al. 2010). Rivers and aquifers are sometimes so interconnected that it is hard to disentangle their effects towards an understanding of the leading physical transport mechanisms of the system and evaluations of the relative roles of fluvial and groundwater compartments (Sophocleous 2002). 
This work focuses on the northern sector of Brenta river (Italy, Figure 1), one of the main recharge portions for the regional groundwater system, together with rain and infiltration originating in fractured mountain domains (Passadore et al. 2015). In this work, we investigate the hydrologic roles of a check dam that has been built, within the domain of MAR works, in order to perform two main functions: i) decreasing the peak river flow downstream thereby reducing the flood risk for the downstream plain; and ii) prompting beneficial increases of the local alluvial aquifer recharge. The specific goal of this study is to assess the efficiency of the check dam in increasing groundwater recharge.

There exist many available methods to study groundwaterriver interactions (e.g. Kalbus et al. 2006; Rosenberry and LaBaugh 2008): seepage runs methods (measuring changes in river flowrate along a stream section), hydrometric methods, or transport tests tracers such as major ions and isotopes (Kumar et al. 2009; Menciò and Mas-Pla 2008) or heat (Anderson 2005; Conant 2004).

The use of heat to study the dispersed flow by the river is indeed interesting (Anderson 2005), because thermal trends in surface and underground compartments are different (Keery et al. 2007). Temperature is easy and cheap to monitor almost continuously, and thermal properties of sediments are much less heterogeneous in space compared to hydraulic conductivity, a limit for hydrometric methods (Stoneman and Constantz 2003).

All methods applied up to now with heat as a tracer start from streambed thermal measures in order to obtain a baseline $1 \mathrm{D}$ problem and, therefore, to evaluate the vertical flowrate upwards or downwards (Anderson 2005; Conant 2004). In particular, Lapham (1989) explains how to use streambed measurements while Anibas et al. (2009) examines their main limitations.
At the field site, a monitoring network has been active since 2007, which continuously records water levels and temperatures. One water gauge in the stream and some probes in riverbanks monitor the natural variables and their recorded temperature's timeseries are analysed. Our main aim is to consider available timeseries as realizations of random processes and analysing them as stochastic processes. Three different analyses are applied to the measured signals: Fourier analysis, that may recognise fluctuations originating from different hydraulic drivers (as explained and used for head records by Acworth et al. 2015); the autocorrelation function, showing how strong is the linear dependency of the parameter depending on the time lag between values, therefore highlighting the persistence and periodicity of the signal; and the Pearson correlation, that underpins the relationship between two series. Kim et al. (2005) applied correlations analyses to show that groundwater discharge rates and precipitation were correlated and that discharges were also autocorrelated in time. These methods can lead to novel insight on the studied system, specifically because they can show the main elements affecting control points, regional groundwater or fluvial dispersion, and therefore the main flow inputs for the experimental locations in time. The time-variant influence of the check dam construction to the groundwater system is not represented as flowrate but as main flow input recognition. A stochastic analysis has thus been applied to records of temperature of stream and groundwater (as in Lee et al. 2013), to highlight the role of each single compartment.

\section{Data and methods}

The monitoring network of the MAR pilot site consists of one water gauge located in the river (WGR), two control points installed on riverbanks downstream the check dam

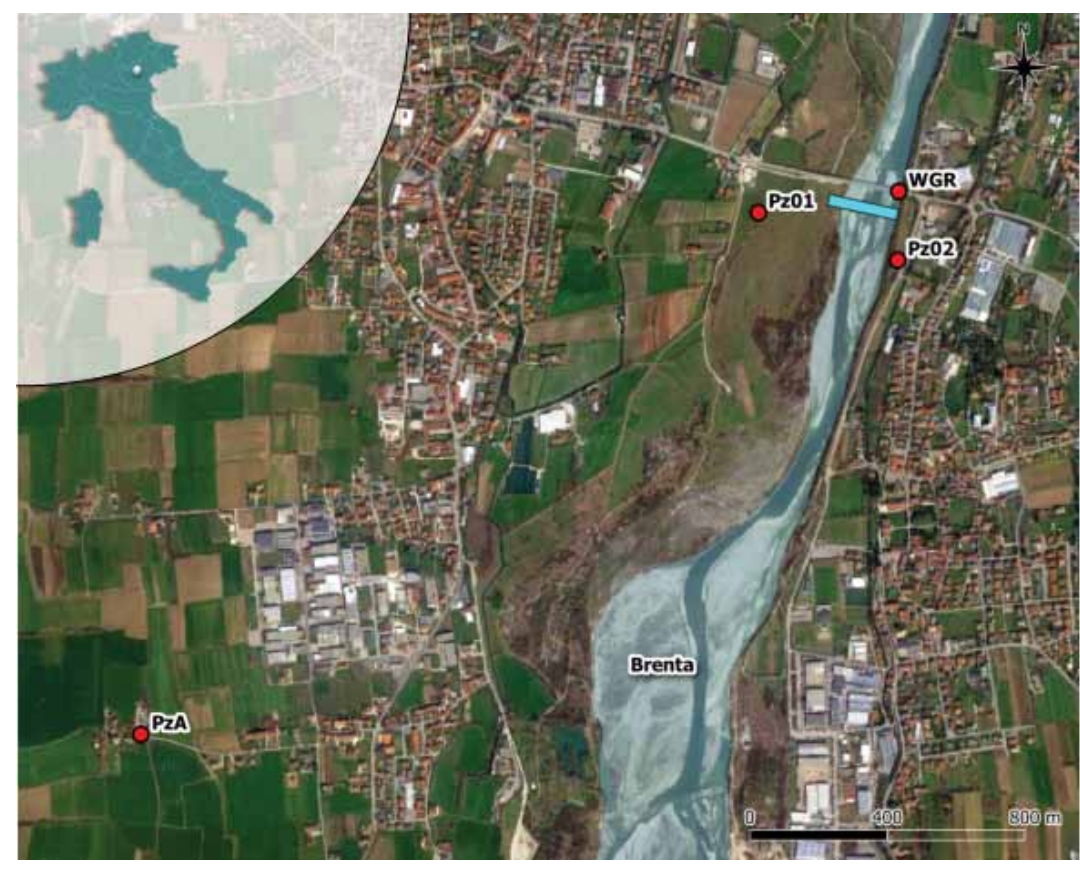

Fig. 1 - MAR pilot site location (light blue bar) and monitoring network (red points).

Fig. 1 - Localizzazione del sito pilota MAR (rettangolo azzurro) e rete di monitoraggio (punti rossi). 


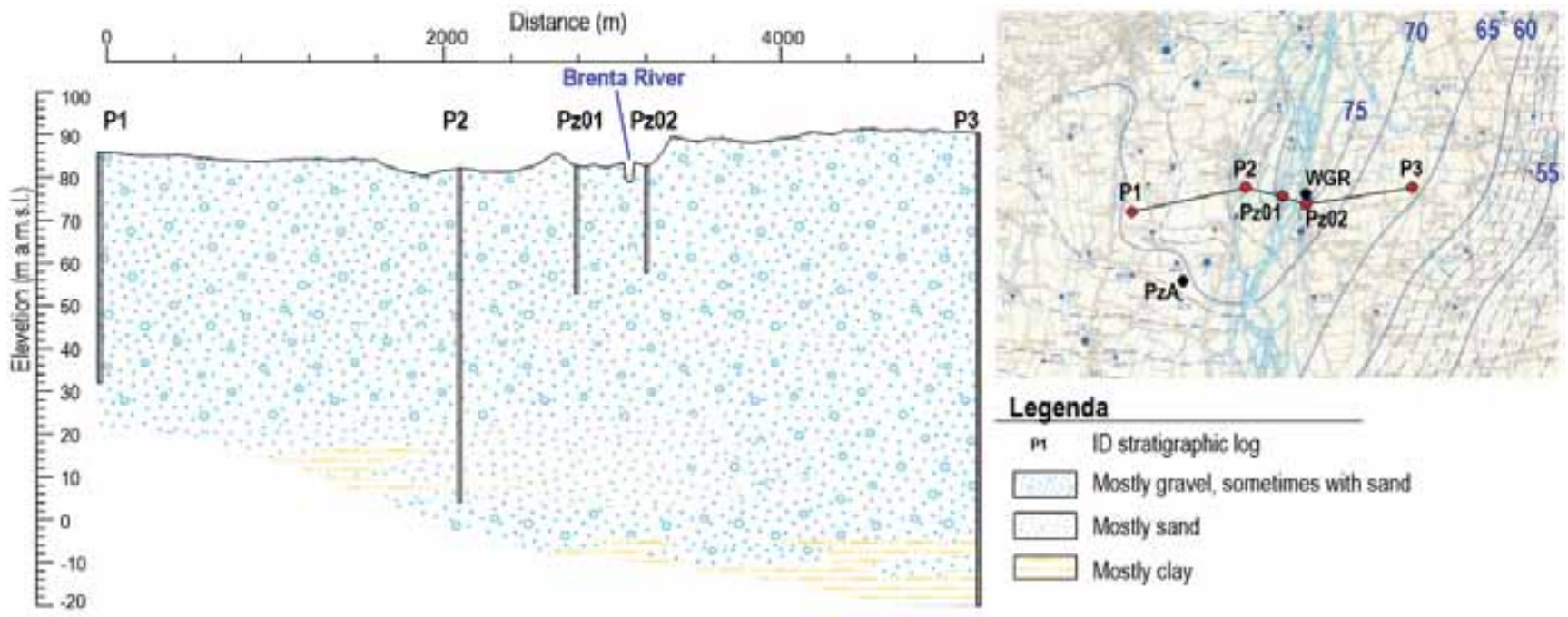

Fig. 2 - Local geological cross-section and extract of the water table map by Antonelli et al. (1980) - Modified.

Fig. 2 - Sezione geologica locale ed estratto della carta isofreatica di Antonelli et al. (1980) - Modificata.

(Pz01 at $300 \mathrm{~m}$ and $\mathrm{Pz} 02$ at $100 \mathrm{~m}$ far from the main stream channel), another control point (PzA) placed $1500 \mathrm{~m}$ far from the river as reference for the groundwater flow. The network setting is shown in Figure 1.

The study area is located above Quaternary deposits, 100 $m$ deep, and resting on a bedrock which elevation is about $-20 \mathrm{~m}$ a.m.s.l. As visible in the cross-section in Figure 2, local stratigraphic logs show materials of fluvio-glacial origins typical of the upper Venetian plain close to the Pre-Alps (Passadore et al. 2015). Therefore, the local hydrogeological setting is an unconfined aquifer which saturated thickness ranges between 80 and $95 \mathrm{~m}$ depending on seasonal fluctuations (see Fig. 3). Moreover, as visible in the water table map, in this area the Brenta river recharges the unconfined aquifer while it changes its behaviour a few kilometres downwards where it drains the aquifer system.
The check dam has been built between October 2008 and February 2009. The riverbank control points have been installed in March 2007, while the farthest control point had been installed previously. The water gauge has been installed in April 2010. All installed probes record water level and temperature every hour. Hourly records have been transformed into daily records. Depending on the studied phenomenon, this conversion can lead to a loss of information. In this specific case it is an acceptable procedure given that the focus is mainly on seasonal thermal variations.

Missing values are present due to faulty sensors, issues with data downloading, or sensors not located deep enough during low stages of the water table. Where complete timeseries are needed, they are simply linearly interpolated in leftovers gaps.

As visible in recorded water level and temperature timeseries in Figure 3, the two riverbank control points have
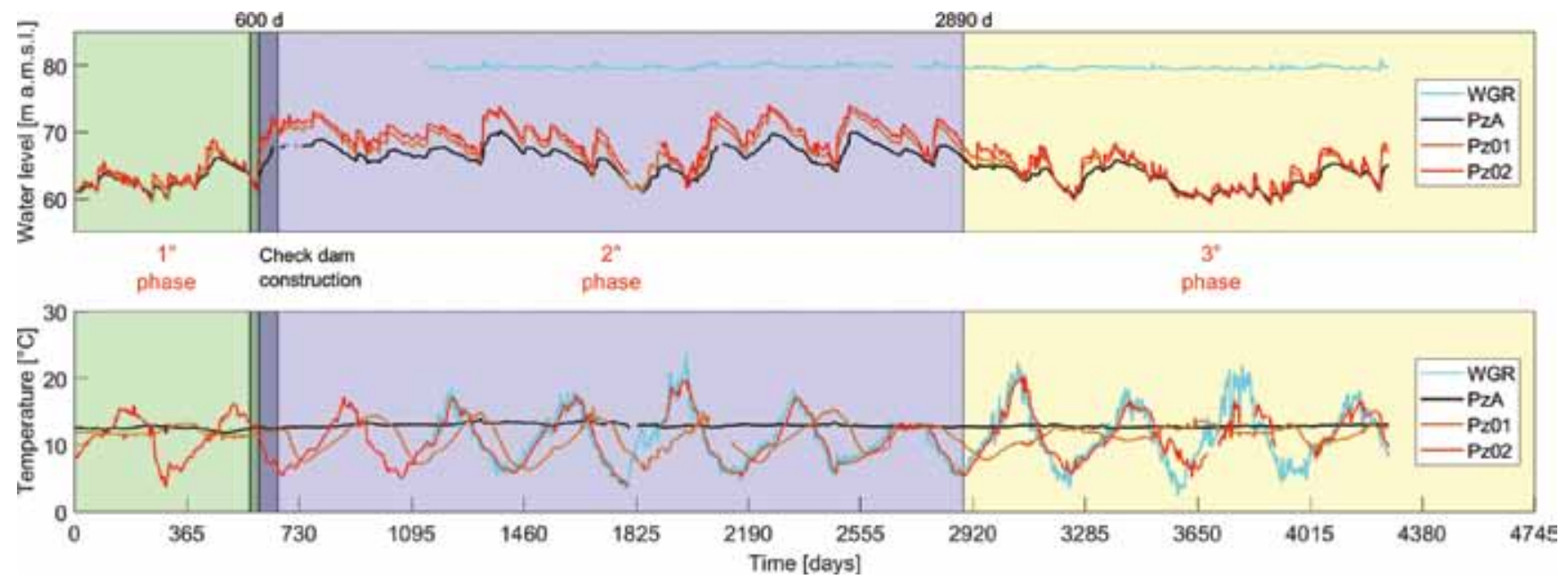

Fig. 3 - Water level and temperature timeseries of the monitoring network.

Fig. 3 - Serie temporali del livello e della temperatura dei sensori appartenenti alla rete di monitoraggio. 
similar hydraulic head trends but differ on thermal behaviour. This simple observation lead to the approximation of neglecting the air temperature effect on groundwater thermal fluctuations. Indeed, given the uniform geological setting of the two control points and the same depth to groundwater, the distinct thermal characteristics are associable mainly with the different river influence on the monitoring points. We therefore consider water temperature variations as clearly indicative of surface water and groundwater interaction.

Looking at daily fragmented thermal timeseries in Figure 3, a few observations arise: i) overall, at visual inspection one concludes that the gaps do not cloud the main features of the signal; ii) the shorter WGR series has a trend similar to that of the $\mathrm{PzO} 2$ series except for daily oscillations; iii) the Pz01 shows a similar behaviour as well, but it is not in phase, the delay ranges about 90 days. Therefore, two assumptions seem justified: assuming WGR missing values prior to the gauge installation equal to the $\mathrm{PzO} 2$ trend and shifting Pz01 timeseries in order to be aligned with the others. The first assumption is necessary to compare the river and the Pz01 trends in the first phase. This way, the behaviour of the control point is qualitatively comparable with both the river and the regional groundwater flow before the check dam construction. Obviously, the comparison between the WGR and the $\mathrm{PzO} 2$ is not meaningful in the first phase.

Regarding the stochastic study carried out on temperature timeseries, three separated analyses are applied. Fourier analyses analyse timeseries into frequency domain (see Appendix), providing a different prospective on series characteristics and insight into hydrologic phenomena (e.g. Bras and Rodriguez-Iturbe 1993). Indeed, resulting power spectra point at local periodicities hardly identifiable in the time domain. Main periodicities depend on the most important flow inputs influencing the recording site. Usually, power spectra are plotted against frequency, here they are plotted against the corresponding period in order to facilitate our understanding of local periodicities. The auto-correlation function (see Appendix) gives insight on signal characteristics such as persistence. It is defined as the Pearson coefficient (Isaaks and Srivastava 1989) considering the same series at different points in time. Then, the present analysis evaluates the sliding time-window Pearson correlation between the measured series. In particular, the Pearson coefficient is not defined for whole series but for a movable window of two years, this way the time-variant correlation is observable. The first two analyses require complete timeseries while the last analysis is applied on fragmented series by considering only periods in which both series have been recorded.

\section{Results}

Starting from the first available results of series comparison in time (Fig. 3), some observations are straightforward. The stream and the regional groundwater flow have a different thermal behaviour: the river shows a seasonally oscillatory trend, ranging between 2.4 and $23.7^{\circ} \mathrm{C}$ (see WGR), while the regional groundwater trend is flatter, oscillating with a range of $2.2^{\circ} \mathrm{C}$ around $12.9^{\circ} \mathrm{C}$ (see $\mathrm{PzA}$ ). Riverbank control points (Pz01 and Pz02) show a different behaviour too, $\mathrm{PzO} 2$ has a clear seasonal trend for the whole recording period, while Pz01 changes behaviour two times. Indeed, three distinct phases are identified (visible in Figure 3): before, just after and five years after the check dam construction (late 2008). All following results are shown for each timeseries in each time phase.

The main result of the Fourier analysis is the power spectrum that identifies main series periodicities. In Figure 4, power spectra are plotted versus the period. They show similar shape for WGR and Pz02 for all phases, looking at both periodicities' identification and energy magnitude. It is important to remark that, for the first phase WGR records are taken from $\mathrm{PzO}$, therefore obviously comparisons between them in the first phase are meaningless. The PzA spectra are always different, in terms of main periodicities and low energy. The most interesting results are represented in $\mathrm{PzO} 1$
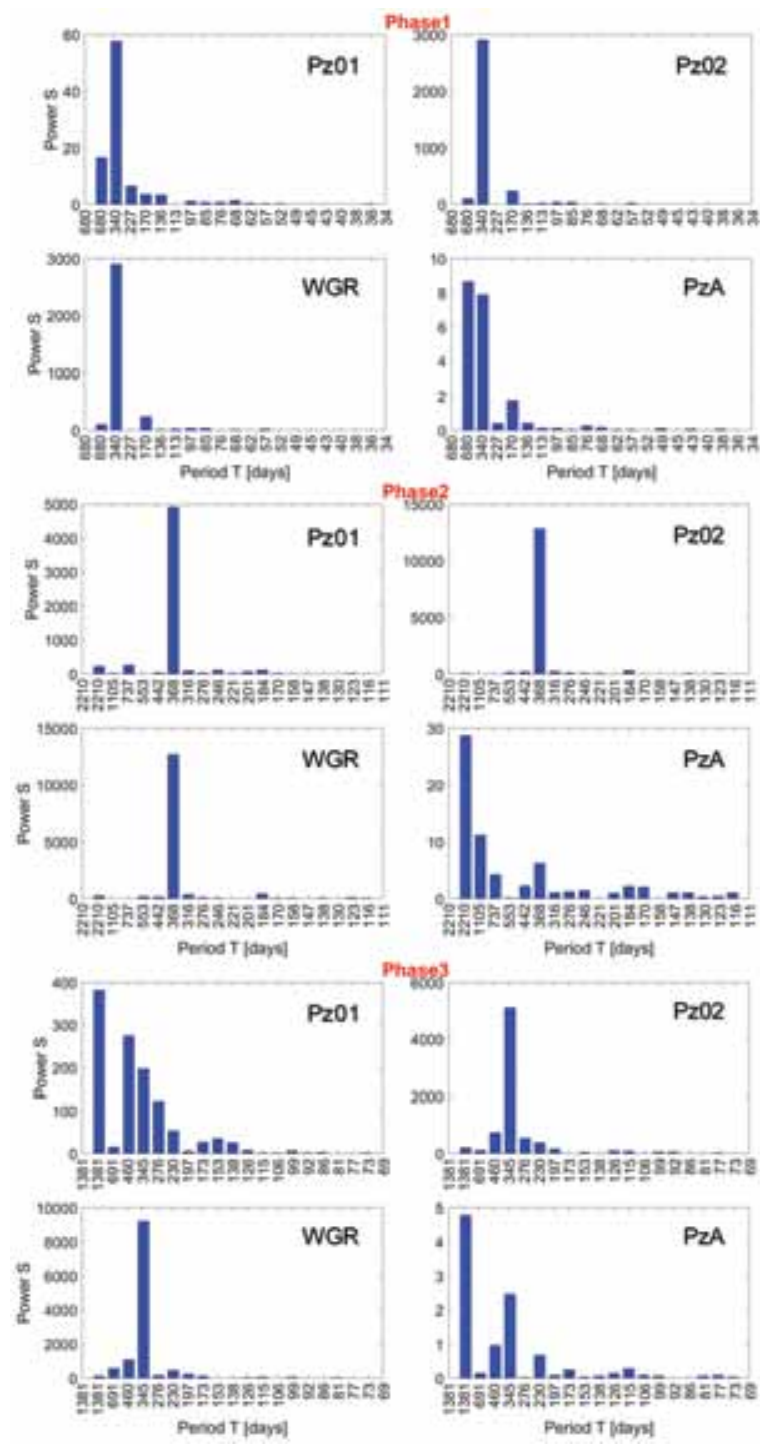

Fig. 4 - Fourier analysis: Power spectra for each series and phase.

Fig. 4 - Analisi di Fourier: spettri di potenza per ogni serie e per ogni fase. 

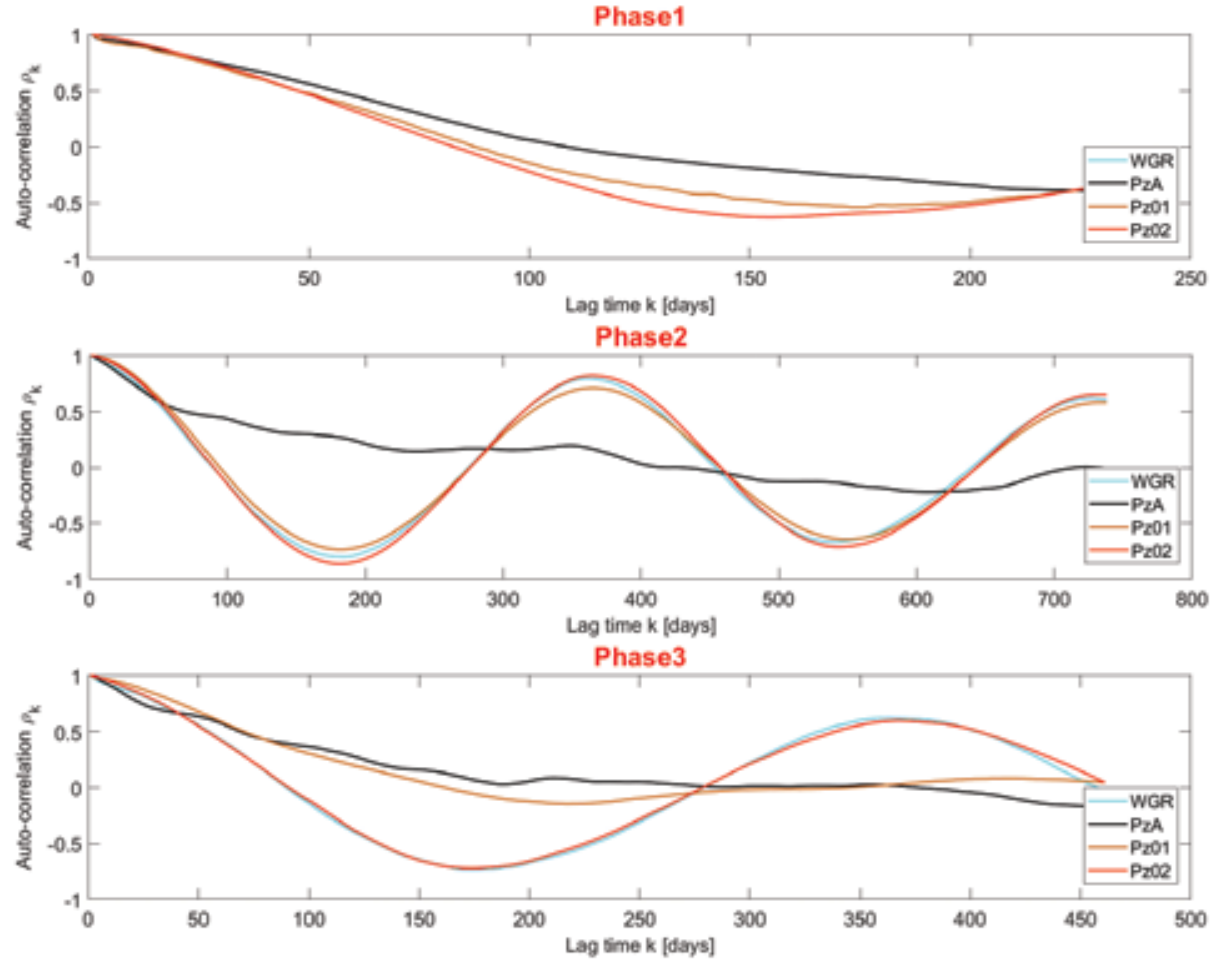

Fig. 5 - Autocorrelation analysis: autocorrelation functions for each phase.

Fig. 5 - Analisi di autocorrelazione: funzioni di autocorrelazione per ogni serie e per ogni fase.

spectra, showing different behaviour depending on the phase: first, it has intermediate peaks and energy magnitude; then its spectrum resembles the one of WGR with lower energy; finally, the power has, as in the first phase, both WGR and PzA peaks with an intermediate energy magnitude.

Autocorrelation functions are defined for each series and in each phase, results are shown in Figure 5. In the first period, functions do not significantly differ due to the short available time interval. On the contrary, functions of the second period clearly show two different behaviours: WGR and riverbank control points nearby exhibit a periodic signal, while PzA exhibits strong persistence but not periodicity.

In the third phase, WGR and $\mathrm{PzO} 2$ still show similar periodic signals and PzA reveals a persistent signal, while $\mathrm{Pz} 01$ has an autocorrelation function much closer to the regional aquifer behaviour, but still with a weak periodicity.

The final analysis is the Pearson correlation of timeseries, in a movable window of two years. It identifies similar behaviours in order to understand if control points are influenced more by the river stage or by the controls imposed by groundwater flow. Figure 6 shows the correlation function Pz02-WGR that proves consistently high with a minimum of 0.8 in the final phase, while it is always low correlated with PzA. Looking at the correlation between PzO1 and WGR, it is high just after the check dam construction ( $2^{\text {nd }}$ phase), but in the first and third phase it is lower.

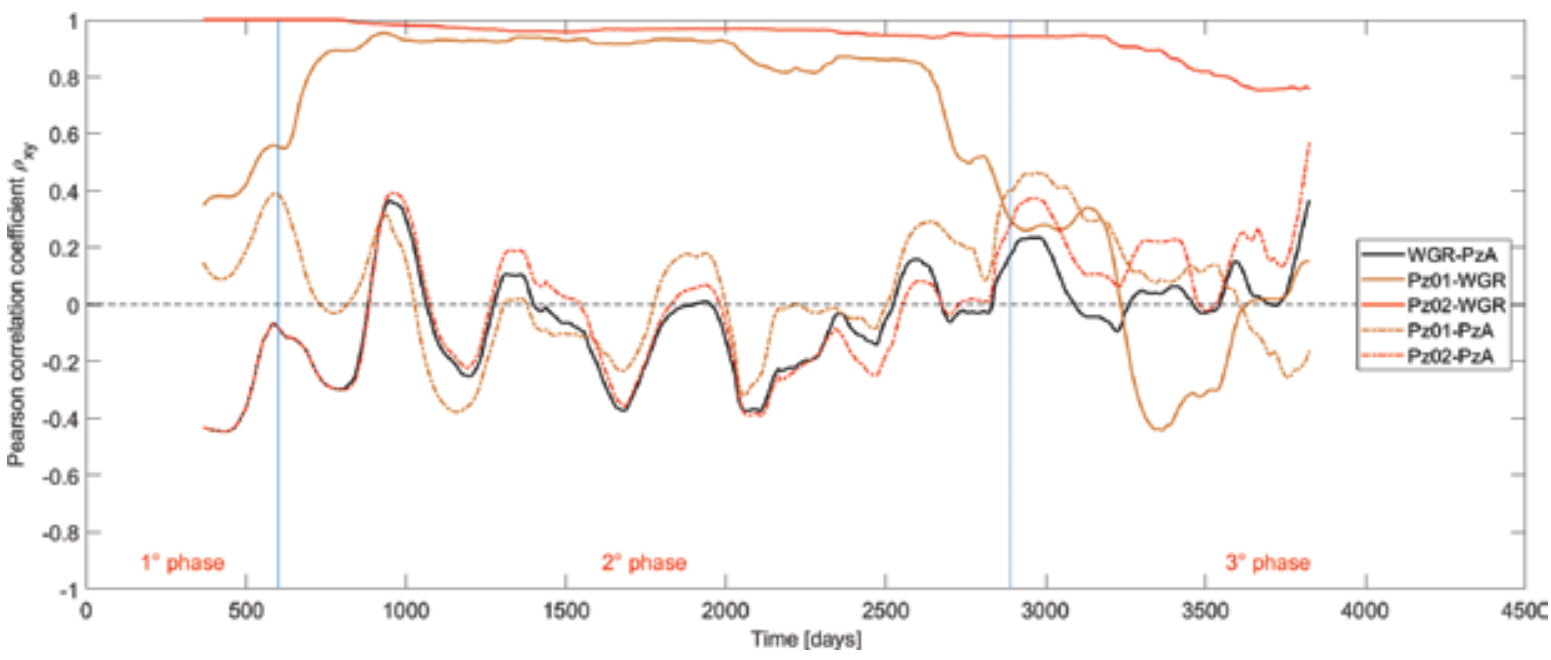

Fig. 6 - Functions of correlation between series of water temperature.

Fig. 6 - Funzioni di correlazione tra serie temporali della temperatura 


\section{Discussion}

The analysis of temperature timeseries returned uniform results that point to similar conclusions. First, prior to the fluvial work's construction, $\mathrm{PzO} 2$ shows thermal oscillations typical of stream waters, confirming the natural river discharge. On the contrary, Pz01 behaviour differs: its temperature barely oscillates, and its trend seems to be more similar to the behaviour of the regional groundwater flow. This is because of its farther position from the main river channel. Second, after the dam construction, the recharge area just upgradient the MAR work increases and the seepage rate to the aquifer raises too. In fact, the examined riverbank control points reproduce the thermal tendency of the river that demonstrates the local role of the dispersion of surface waters in both sites. Third, in the last phase, both riverbank control points are less influenced by the stream, even if $\mathrm{PzO} 2$ has always a greater proximity to the river trend than the regional groundwater one. Two concurrent phenomena may explain these latter results: the river is slowly creating a preferential narrower pathway closer to $\mathrm{PzO} 2$ than Pz01; and there could be some clogging phenomena (Hutchison et al. 2013). This clogging would cause a permeability reduction of the riverbed due to the porosity obstruction by fine material. Further studies may look at whether any of these two proposed explanations has a stronger role.

\section{Conclusions}

In the high alluvial plain, the Brenta river is one of the most important recharging factors for the local unconfined aquifer. A check dam has been implemented on its streambed, in order to further increase the river seepage and preserve the groundwater resource. Indeed, the aquifer system is highly exploited for public as well as private uses. The purpose of this study is to understand the efficiency of the dam with respect to the artificial increase in dispersed flow rate. To this goal, this study uses heat as a natural tracer for surfacegroundwater connections, using the temperature timeseries of an existing monitoring network. It applies three different statistical analyses to timeseries in each phase, which have been identified by looking at changes on time domain trends.

The three analyses agree on the results: i) the farther riverbank control point showed, at first, no correlated signal; however, after the check dam construction, it is clearly affected by fluvial dispersion; ii) five years after the check dam installation, both control points are less influenced by the river trend. These observations can respectively lead to two general understandings. First, the check dam construction causes an increased recharge area upstream the MAR work, increasing the artificial recharge and affecting a larger groundwater portion. Moreover, the recharge decreases its effectiveness on groundwater after five years.

More general conclusions regarding the applied analysis are: i) the results agreement on flow inputs affecting the groundwater system, ii) its capacity to detect changes in size of the recharge area and fluvial dispersion effectiveness, for example by showing the effects of clogging phenomena.

\section{APPENDIX \\ Applied statistical analyses}

Hydrological processes can be represented with the aid of random functions.

As explained in Maione and Moisello (1993), given the variable $t$ defined in the interval $(0 ; \mathrm{T})$ and the variable $x$ dependent on the first by the relation $x=g(t)$, by also considering the functions ensemble $g_{i}(t)$ defined in the same time interval, and by supposing that $x$ can coincide casually with one of the functions, this definition entails the $x$ randomness. The Fourier analysis moves timeseries into the frequency domain. It is based on the idea that a deterministic signal can be approximated as sum of simpler trigonometric functions (Bras and Rodriguez-Iturbe 1994). Considering that series to analyse are not continuous, but sequences of values measured at regular time intervals $\Delta \mathrm{t}$, series available are sample chains of $\mathrm{N}$ observations. In this case, the Fouriertransform pair is:

$$
\begin{aligned}
& X_{f}=\sum_{n=0}^{N-1} X_{n} e^{i 2 \theta \frac{f n}{N}} \\
& X_{n}=\sum_{f=0}^{N-1} X_{f} e^{i 2 \theta \frac{f n}{N}}
\end{aligned}
$$

In order to define series in the frequency domain, the Fast Fourier Transform is the fastest algorithm. In this analysis the MATLAB code is used, it is applied by using the fft function and it returns the frequency domain representation $\mathrm{X}(\mathrm{f})$.

Then, the power spectrum is defined as:

$$
S_{f}=\frac{\operatorname{Re}^{2} X(f)+\operatorname{Im}^{2} X(f)}{N}
$$

where $f$ ranges between 0 and $N-1$. Given the complex nature of $X$, the power spectrum is symmetric. Indeed, first $N / 2$ components are complex conjugates of other N/2 terms. It is therefore enough to plot and analyse half the spectrum. In this work, spectra are plotted against the period $T$ instead of against the frequency $f$. The conversion is simply on the $\mathrm{x}$-axis by using the formula:

$$
f=\frac{1}{T}
$$

The probability distribution of the dependent variable $x$ is usually not only dependent from the value of $t$, but also from previous values of $x$.

Given the discrete nature of the analysed timeseries, each element corresponds to a time interval $\mathrm{i}$ ranging between 1 and $N$. Considering two different time instants $i$ and $i+k$, 
between infinite possible values for variable $x_{i}$ and for $x_{(i+k)}$ it exists a bijective correspondence belonging to the same realization of the process. It is possible to say there is a joint probability distribution between the two variables and an important descriptive parameter is the linear autocorrelation coefficient of order $\mathrm{k}, \rho_{k}\left(x_{i}\right)$. Assuming a stationary stochastic process, the autocorrelation coefficient loses its dependency in time and it depends only on the time lag $\mathrm{k}\left(\rho_{\mathrm{k}}\right)$. In order to define the autocorrelation coefficient for the sample, the following equations have to be used:

$$
\begin{aligned}
& \sigma^{2}=\frac{1}{N-1} \sum_{i=1}^{N}\left(x_{i}-\mu\right)^{2} \\
& c_{k}=\frac{1}{N} \sum_{i=1}^{N-k}\left(x_{i}-\mu\right)\left(x_{i+k}-\mu\right) \\
& \rho_{k}=\frac{c_{k}}{\sigma^{2}}
\end{aligned}
$$

where $\sigma^{2}$ is the sample variance, $\mu$ is the sample mean, $c_{k}$ is the covariance of order $k$. The autocorrelation function reports the coefficient depending on the time lag $k$. The parameter is evaluated in MATLAB with the autocorr function.

The sliding time-window correlation is evaluated by defining the Pearson correlation coefficient between two different timeseries $x$ and $y$. The coefficient formula has a similar structure to Eq. 7:

$\rho_{x y}=\frac{c_{x y}}{\sigma_{x} \sigma_{y}}=\frac{\sum_{i=1}^{N-k}\left(x_{i}-\mu_{x}\right)\left(y_{i}-\mu_{y}\right)}{\sqrt{\sum_{i=1}^{N}\left(x_{i}-\mu_{x}\right)^{2}} \sqrt{\sum_{i=1}^{N}\left(y_{i}-\mu_{y}\right)^{2}}}$

The parameter is evaluated in MATLAB with the corr function.

\section{REFERENCES}

Acworth R, Rau GC, McCallum AM, Andersen MS, Cuthbert MO (2015) Understanding connected surface-water/groundwater systems using Fourier analysis of daily and sub-daily head fluctuations. Hydrogeology Journal, 143-159.

Anderson MP (2005) Heat as a ground water trace. Groundwater, 951-968.

Anibas C, Fleckenstein JH, Volze N, Buis K, Verhoeven R, Meire P, Batelaan O (2009) Transient or steady-state? Using vertical temperature profiles to quantify groundwater-surface water exchange. Hydrological Processes: An International Journal, 2165-2177.

Antonelli R, Dal Prà A (1980) Carta dei deflussi freatici dell'alta pianura veneta con note illustrative "Map of the phreatic flows of the upper Venetian plain with illustrative notes". Istituto di Ricerca sulle Acque.

Bras RL, Rodriguez-Iturbe I (1993) Random functions and hydrology. Courier Corporation.

Conant BJ (2004) Delineating and quantifying ground water discharge zones using streambed temperatures. Groundwater, 243-257.

Hayashi M, Rosenberry DO (2002) Effects of Ground Water Exchange on the Hydrology and Ecology of Surface Water. Groundwater, 309-316.

Hutchison A, Milczarek M, Banerjee M (2013) Clogging phenomena related to surface water recharge facilities. Clogging Issues Associated with Managed Aquifer Recharge Methods; Martin, R., Ed, 34-49.

Isaaks EH, Srivastava RM (1989) An introduction to applied geostatistics. Oxford University Press.

Kalbus E, Reinstorf F, Schirmer M (2006) Measuring methods for groundwater? surface water interactions: a review. Hydrology and Earth System Sciences Discussions, 873-887.

Keery J, Binley A, Crook N, Smith JW (2007) Temporal and spatial variability of groundwater--surface water fluxes: development and application of an analytical method using temperature time series. Journal of Hydrology, 1-16.

Kim SJ, Hyun Y, Lee KK (2005) Time series modeling for evaluation of groundwater discharge rates into an urban subway system. Geosciences Journal, 15.

Kumar M, Ramanathan A, Keshari A (2009) Understanding the extent of interactions between groundwater and surface water through major ion chemistry and multivariate statistical techniques. Hydrological Processes: An International Journal, 297-310.

Lapham WW (1989) Use of temperature profiles beneath streams to determine rates of vertical ground-water flow and vertical hydraulic conductivity. Dept. of the Interior, US Geological Survey.

Lee JY, Lim H, Yoon H, Park Y (2013) Stream water and groundwater interaction revealed by temperature monitoring in agricultural areas. Water, 1677-1698.

Maione U, Moisello U (1993) Elementi di statistica per l'idrologia "Statistical elements for bydrology". La Goliardica.

Menciò A, Mas-Pla J (2008) Assessment by multivariate analysis of groundwater--surface water interactions in urbanized Mediterranean streams. Journal of hydrology, 355-366.

Passadore G, Sottani A, Putti M, Rinaldo A (2015) Groundwater thermal monitoring to characterize streambed water fluxes of the Brenta river (Northern Italy). Procedia Environmental Sciences, 199-205.

Rinaldo A, Altissimo L, Putti M, Passadore G, Monego M, Sottani A (2010) Modello matematico di flusso nei sistemi acquiferi dei territori dell'Autorità d'Ambito Territoriale Ottimale ATO Brenta "Matbemacical model of flow in aquifers in the area of the "Autorità d'Ambito Territoriale Ottimale ATO Brenta". Università degli Studi Di Padova, Centro idrico di Novoledo, Provincia di Padova, Provincia di Vicenza, ATO Brenta, Relazione finale.

Rosenberry DO, LaBaugh JW (2008) Field techniques for estimating water fluxes between surface water and ground water. Geological Survey (US).

Sophocleous M (2002) Interactions between groundwater and surface water: the state of the science. Hydrogeology journal, 52-67.

Stoneman DA, Constantz J (2003) Heat as a tool for studying the movement of ground water near streams. US Department of the Interior, US Geological Survey. 